\title{
Pengembangan Kepemimpinan Berbasis Budaya (Studi Kasus di RW 05 Kelurahan Baktijaya Kecamatan Setu Tangerang Selatan)
}

\author{
Teguh Yuwono' ${ }^{1}$ Angga Rovita ${ }^{2}$, Diana Riyana $\mathbf{H}^{3}$ \\ 1,2,3 Universitas Pamulang, Banten, Indonesia \\ E-mail: dosen00726@unpam.ac.id
}

\begin{abstract}
Article Info
Article History

Received: 2021-05-12

Revised: 2021-08-15

Published: 2021-08-24

Keywords:

Development;

Leadership;

Culture.

Abstract

This study aims to analyze whether the values of culture-based leadership that are applied can be accepted and implemented well by the employees they lead so as to produce a good synergy between the leaders and the citizens of Bakti Jaya. This study used qualitative research methods. This research was carried out in RW 05, Bakhti Jaya Village, Setu District, South Tangerang. The result of this research is that every institution, institution and organization, whatever its name, must make changes. Because the dynamics of life move very quickly. The challenge is not only to be able to adapt to change, but also how to determine the direction of change and lead change. Likewise in RW 05 an Baktijaya Village, Setu District, South Tangerang. After a very long leadership period there was no change, the new RW chairman made a breakthrough by creating a NEW slogan (Clean-Safe-Rukun). From this slogan, leadership was developed to its lower level, namely to the RT until it touched the plains of community reality. By cultivating the word NEW, the head of the RW has succeeded in implementing community values which in turn creates leadership values in the community. Thus, the Chairperson of RW 05 succeeded in developing culturebased leadership.
\end{abstract}

\begin{abstract}
Abstrak
Penelitian ini bertujuan untuk Menganalisa apakah nilai-nilai kepemimpinan berbasis budaya yang diterapkan dapat diterima dan diimplementasikan dengan baik oleh pegawai yang dipimpinnya sehingga menghasilkan sinergi yang baik antara pemimpin dan warga Bakti Jaya. Penelitian ini menggunakan metode penelitian kualitatif. Penelitian ini dilaksanakan pada rw 05 Kelurahan bakhti jaya kecamatan setu Tangerang Selatan. Hasil dari penelitian ini adalah Setiap lembaga, institusi dan organisasi apapun namanya tentu harus melakukan perubahan. Karena dinamika kehidupan bergerak terus dengan sangat cepat. Tantangannya bukan saja harus mampu beradaptasi dengan perubahan, namu juga bagaimana kemampuan menentukan arah perubahan serta memimpin perubahan. Begitu pula di ke RW 05 an Kelurahan Baktijaya Kecamatan Setu Tangerang Selatan. Paska kepemimpinan yang sangat lama tidak ada perubahan, maka ketua RW yang baru ini melakukan terobosan dengan membuat slogan BARU (Bersih -Aman-Rukun). Dari slogan ini dikembangkan kepemimpinan ke level bawahnya yaitu ke RT dan sampai menyentuh dataran realitas masyarakat, dengan membudayaan kata BARU, ketua RW berhasil mengimplementasikan nilai-nilai kemasyarakatan yang pada gilirannya tercipta nilai- nilai kepemimpinan di lapiran masyarakatnya, dengan demikian Ketua RW 05 berhasil mengembangkan kepemimpinan berbasis budaya.
\end{abstract}

\section{PENDAHULUAN}

Pemimpin merupakan ujung tombak dari sebuah kehidupan, jika ujung tombak itu tumpul maka kehidupan dapat vakum dan tidak berdaya guna serta menjadi tidak efektif, untuk lebih mendalami pengertian kepemimpinan, dikemukakan beberapa pengertian kepemimpinan baik ditinjau dari filosofinya, sejarahnya, legalitasnya, kepemimpinan masa kini, kegalauan kepemimpinan dan fenomena kepemimpinan, oleh karena itu epemimpinan dipandang sangat penting karena pada hakikatnya terkandung sifat- sifat kepribadian (personality), kemampuan (ability), kesanggupan (capability), kepemimpinan juga merupakan rangkaian kegiatan (activity) yang tidak dapat dipisahkan dengan kedudukan (posisi) serta gaya atau perilaku pemimpin itu sendiri Menurut Sanusi dalam Usman (2011), menyatakan bahwa kepemimpinan adalah penyatu paduan dari kemampuan, cita-cita, dan semangat kebangsaan dalam mengatur, 
mengendalikan, dan mengelola rumah tangga keluarga atau rumah tangga negara maupun organisasi, seorang dengan wewenang kepemimpinannya mengarahkan bawahannya untuk mengerjakan sebagian dari pekerjaannya dalam mencapai tujuannya, Organisasi adalah sebuah miniatur Negara yang didalamnya terdapat struktur, kepemimpinan pada pemerintahan pusat terdapat presiden, kepemimpinan pada pemerintahan tingkat provinsi terdapat gubernur dan kepemimpinan pada tingkat kabupaten/kota terdapat bupati/ walikota.

Dalam tingkatan tersebut terdapat sinergitas antara yang satu dengan yang lainnya, menurut Hasrul (2013), keberhasilan suatu proses kelembagaan terletak pada munculnya pemantapan koordinasi dan memperkuat sinergitas agar terwujud efektivitas dan efisiensi penyelenggaraan pemerintahan/kelembagaan, serta memegang kekuasaan, seorang pemimpin yang dapat mengatur atau mengatur segala sesuatu yang berhubungan organisasi atau instansi yang dipimpinnya demi tercapainya suatu tujuan tertentuPemimpin adalah tulang punggung organisasi, memajukan dan mendorong organisasi serta membuat perubahan untuk mencapai hasil semaksimal mungkin, Pemimpin harus mengembangkan budaya organisasi yang dapat menunjang pencapaian visi dan misi organisasi yang telah ditetapkan.

Budaya organisasi dimaksud yaitu pola perilaku meliputi pemikiran, tindakan, bahasa dan kebiasaan yang dilakukan oleh anggota organisasi, beberapa nilai yang dibagi atau dirasakan bersama oleh anggota suatu organisasi, norma, kepercayaan, asumsi para anggota organisasi untuk mengelola masalah dan pengaruh di sekitarnya, budaya organisasi berfungsi sebagai penjamin kelangsungan hidup organisasi yang terdapat nilai fundamental organisasi yang baik seperti menjunjung tinggi nilai kejujuran dan integritas, penghargaan atas disiplin, pelayanan yang prima dan penghormatan atas keterbukaan, budaya organisasi dapat terlaksana dengan baik, apabila pemimpin mampu menjalankan fungsinya sesuai dengan perannya, artinya bahwa peranan pemimpin dapat mempengaruhi, menggerakkan dan mengarahkan bawahan supaya perilaku anggota sesuai dengan aturan yang telah ditetapkan yang dapat berdampak terbentuknya budaya organisasi, dalam lingkungan kompetitif yang berubah, ada kebutuhan untuk mengembangkan organisasi dan fasilitas secara signifikan yang lebih fleksibel dan responsif dari yang sudah ada, para pemimpin sebagai salah satu pihak yang berkepentingan berada pada garis terdepan dalam mewujudkan perubahan karena dituntut dan diberi tanggung jawab oleh berbagai pihak yang berkepentingan lainnya untuk mampu menjalankan roda organisasi sedemikian rupa.

Keberhasilan para pemimpin menanggapi perubahan yang terjadi memerlukan gaya kepemimpinan yang sesuai dengan tuntutan perubahan tersebut, dalam hal ini, faktor budaya organisasi (culture organization) menjadi penting artinya bagi seorang pemimpin, budaya organisasi merupakan salah satu faktor penting yang sangat menentukan terhadap berhasil tidaknya organisasi tersebut, untuk itu, peranan pemimpin dalam upaya membentuk dan membangun budaya organisasi yang kondusif bagi pencapaian tujuan organisasi sangatlah menentukan, RW 05 Kelurahan Bahkti Jaya Kecamatan Setu Tangerang selatan dalam melakukan kegiatannya berharap dapat melaksanakan produktivitasnya secara efisien, sesuai dengan rencana yang telah ditetapkan, mengingat pentingnya peranan pemimpin dalam membentuk budaya organisasi yang diterapkan RW 05 Kelurahan Bahkti Jaya Kecamatan Setu Tangerang selatan, berdasarkan uraian diatas, maka peneliti tertarik menganalisa lebih lanjut mengenai "Pengembangan Kepemimpinan Berbasis Budaya (Studi Kasus di RW 05 Kelurahan Baktijaya Kecamatan Setu Tangerang Selatan )".

Berdasakan Fokus masalah di atas, maka ditetapkan tujuan dari penelitian ini diantaranya: (1) Mengindentifikasi nilai-nilai kepemimpinan berbasis budaya yang diterapkan oleh pemimpin RW 05 Kelurahan Bakti Jaya, (2) Menganalisa apakah nilai-nilai kepemimpinan berbasis budaya yang diterapkan dapat diterima dan diimplementasikan dengan baik oleh pegawai yang dipimpinnya sehingga menghasilkan sinergi yang baik antara pemimpin dan warga Bakti Jaya.

\section{METODE PENELITIAN}

Penelitian ini menggunakan metode penelitian kualitatif, Menurut Moleong (2007), 
penelitian kualitatif adalah penelitian yang bermaksud untuk memahami fenomena tentang apa yang dialami oleh subyek penelitian misalnya: perilaku, persepsi, motivasi, tindakan secara holistik dan dengan cara deskripsi dalam bentuk kata-kata dan bahasa, pada suatu konteks khusus yang alamiah dan dengan memanfaatkan berbagai metode alamiah. Sedangkan metode deskriptif adalah suatu metode dalam meneliti status sekelompok manusia, suatu objek, suatu set kondisi, suatu sistem pemikiran, ataupun suatu kelas peristiwa pada masa sekarang.

Tujuan dari penelitian deskriptif adalah untuk membuat deskripsi, gambaran atau lukisan secara sistematis, faktual dan akurat mengenai fakta-fakta, sifat-sifat serta hubungan antar fenomena yang yang diselidiki (Nazir, 2013). Penelitian ini berusaha untuk mencari gambaran/deskripsi mengenai bagaimana paradigma mahasiswa program studi manajemen Universitas Pamulang terhadap kewirausahaan. Hal ini dikarenakan adanya keluwesan yang tinggi dalam mendapatkan informasi dari tangan pertama (first hand informan), yaitu RW 05 Kelurahan bakhti jaya kecamatan setu Tangerang Selatan, selain hal tersebut di atas, penelitian ini juga menggunakan Metode Focus Group Discussion sebagai salah satu bentuk penelitian kualitatif, yang merupakan wawancara kelompok yang ditekankan pada interaksi atas topik yang disodorkan.

Pada penelitian ini akan dipaparkan pengujian validitas data, keabsahan data atau kredibilitas data. Yaitu dengan pengamatan, peningkatan ketekunan, diskusi dan kajian serta analisa terhadap kasus kepemimpinan. Validitas Kontruk; Validitas Internal;Validitas Eksternal; Reliabilitas; Dalam penelitian, pengumpulan data sangat penting dan harus diperhatikan dengan baik, terutama data yang relevan terhadap penelitian. Lebih lanjut menurut Umi (2013) terdapat enam macam sumber bukti yang bisa digunakan dalam penelitian studi kasius, yaitu : dokumen, rekaman arsip, wawancara, pengamatan langsung, observasi partisipan dan perangkat -perangkat fisik. Datadata yang digunakan dalam penelitian ini adalah dari referensi buku, majalah, weeb site, wawancara, grup diskusi dan sebagainya

Dalam melakukan analisis terhadap berbagai data yang masuk, peneliti menggunakan Chain of Evidence, yaitu melakukan analisis secara mendalam dan komprehensif mengenai obyek penelitian, dimulai dengan memaparkan identifikasi nilai dan budaya yang dilanjutkan dengan pengamatan secara cermat, sehingga ditemukan kesenjangan budaya. Dan tentu saja dengan ditemukannya kesenjangan budaya akan didapatkan perubahanperubahan budaya dengan munculnya nilainilai terutama dari RW 05 Kelurahan bakhti jaya kecamatan setu Tangerang Selatan

\section{HASIL DAN PEMBAHASAN}

Berbagai temuan dalam penelitian, baik yang didapat dari observasi, wawancara maupun focus grup diskusi penulis kritisi, Hal ini untuk menegaskan bahwa penelitian ini bukan hanya kualitatif sifatnya, namun juga memberi bobot serta nilai tambah sebagai masukan kepada jajaran pengurus RW 05 Kelurahan Baktijaya - Setu Tangerang Selatan, Dalam visi misi yang dicanangkan RW dapat digarisbawahi bahwa "strategi kepemimpinan yang digunakan dalam membangun lingkungan adalah dengan membangun sumber daya manusia seluruh pengurus RT, yaitu dengan menumbuhkembangkan nilainilai kemasyarakatan."Keterkaitan nilai-nilai luhur dalam bekerja sangatlah penting karena bukan saja akan mengarahkan semangat bekerja, namun akan tetap terus berkembangnya etos kerja, Dalam pandangan peneliti terjadi pengembangan nilai-nilai kepemimpinan yang dilakukan, yaitu "Strategi kepemimpinan yang digunakan dalam membangun masyarakat mengedepankan kekeluargaan da kerukunan, artinya budaya kekeluargaan sangat dikedepankan, namun membangun kepemimpinan itu tidak cukup hanya berbasis budaya (sifat-sifat kekeluargaan) saja, namun juga harus mempertimbangkan struktur dari proses dalam pengembangannya, terutama dalam transformasi nilai-nilai guna pembentukan nilai-nilai kepemimpinan baru atau yang di bawahnya.

Kerangka berpikir yang peneliti lakukan dalam penelitian tentang kepemimpinan di RW 05 ini adalah dimulai dari Visi, Misi dan Struktur Orgaisasi kepemimpinan yang dijalankan, kemudian dengan dukungan nilainilai saat ini diarahkan menuju terbangunnya nilai-nilai baru sesuai yang diharapkan, hal tersebut dapat diketahui dari fungsi dan tanggungjawab utama seorang pemimpin, dalam hal ini adalah ketua RW 05, untuk 
mengarahkan para ketua RT termasuk pengurusnya dan masyarakat di dalamnya agar mampu berkembang. Indicator utama dari sebuah kepemimpinan dapat dilihat dari Core Competence, Soft Competence dan Soft Competence-nya, karena hal inilah yang akan mengarahkan kompetensi seorang pemimpin dengan basis nilai-nilai ( budaya).

Penelitian melihat bahwa kerangka konseptual yang dibuat cukup relevan dan berlaku untuk mengkaji masalah kepemimpinan dengan basis nilai-nilai, hanya saja perlu pengembangan dalam kerangka tersebut, karena sebuah kepemimpinan itu tidak hanya menyangkut struktur saja, namun juga menyangkut system/proses dan budaya, terutama dalam hal kinerjanya.

\section{Perspektif Peneliti}

Terkait dengan temuan-temuan dalam penelitian tentang kepemimpinan di RW 05, peneliti membuat perspektif dari 3 sisi :

Pertama $\rightarrow$ dari perspektif coverage area

Secara mikro, kepemimpinan berbasis kekeluargaan (budaya) dapat memberi nilai lebih kepada Ketua RW dan masyarakatnya.

Secara makro, kepemimpinan berbasis nilai-nilai budaya tersebut dapat memberi nilai tambah kepada lembaga ke RW an dan Kelurahan serta kecamatan..

Secara Nasional, kepemimpinan berbasis nilai-nilai (budaya) dapat memberi nilai tambah kepada Negara. Setidaknya sebagai bentuk kearifan lokal.

Secara Regional, kepemimpinan berbasis nilai-nilai (budaya) dapat memberi nilai tambah antar Negara di tingkat Asia.

Secara Global, kepemimpinan berbasis nilai-nilai (budaya) dapat memberi nilai tambah di dunia internasional.

Kedua $\rightarrow$ dari perspektif waktu (Time Frame) Kepemimpinan dari perspektif waktu atau time frame ada tiga masa, yaitu masa lalu terkait dengan old values, masa sekarang terkait dengan realitas dan masa depan sebagai new version.

Ketiga $\rightarrow$ dari perspektif spiritual (spiritual vertical)

Kepemimpinan berbasis nilai-nilai dalam arti spiritual, dapat dijadikan sebagai: (1) Titik penemuan jati diri, (2) Garis yang membidang untuk membentengi pengaruh dari luar, (3) Sebagai sesuatu yang dapat lebih mendekatkan diri kepada Tuhan Yang
Maha Esa, yaitu sebuah upaya menuju rahmatan lil'alamin.

\section{Tantangan Kepemimpinan}

Dalam dataran dinamika kehidupan, globalisasi telah meruntuhkan temboktembok penyekat antar bangsa dan Negara, Hal ini berarti pertautan antar Negara semakin kuat dan tiada batas, oleh karena itu, penguatan disetiap sektor kehidupan harus terjadi dan tak terkecuali masalah kepemimpinan, masalah global bidang kemasyarakatan adalah adanya pergerakan (perubahan) karakter dan budaya manusianya, terlebih dengan mulai banyaknya lembaga-lembaga atau organisasi masyarakat ( ormas) yang memberi implikasi pada: (1) Tuntutan masyarakat yang makin complicated, (2) Peraturan terkait masalah kemasyarakatan yang makin ketat, (3) Regulasi pemerintah yang makin ketat, (4) Kehidupan masyarakat yang makin berkembang, (5) Tuntutan pelayanan para pengurus RW, RT yang makin prima, (6) Tuntutan solution oriented

Hal-hal tersebut di atas menjadi tantangan yang tidak mudah untuk dihadapi bagi kepemimpinan di level RT dan RW yang lansung bersentuhan dengan masyarakat . Terlebih kepemimpinan pada dataran realitas yang memiliki tugas tidak ringan. Dan akan lebih sulit lagi bila pemimpin yang hanya memahami kultur atau nilai dan norma yang telah menetap lama yang telah dijalankan tanpa melihat nilai-nilai baru di era global ini.

\section{Mengatasi Tantangan Kepemimpinan}

Tantangan yang dihadapi oleh pemimpin sangatlah berat, maka perlunya strategi bagaimana memenangi persaingan global, untuk itu seorang pemimpin dituntut untuk mengembangkan hal-hal sebagai berikut:

a. Human Capital Investment (HCI), yaitu investasi di bidang pengembangan SDM kepada seluruh pengurus dan masyarakat. Hal ini sangat penting mengingat persaingan dunia pendidikanpun begitu berat. Para pesaing dunia pendidikan bukan hanya pekerja lokal, namun juga pekerja asing yang tinggal di Indonesia. Begitu pentingnya pengembangan SDM bagi sebuah institusi pendidikan, maka sering didengar sebuah pernyataan mengenai pentingnya pekerja (guru) sebagai asset, "put people first in the global 
economy", serta untuk mensejajarkan diri kepada tenaga kerja asing.

b. Information Technology (IT) / Enhancement System, yaitu penyempurnaan di bidang teknologi agar memudahkan kerja, terutama dalam mengajar. Misalnya dengan infocus, laptop dan sebagainya.

c. Networking (Expansive Enlargement), yaitu perluasan kemitraan maupun kerjasama dengan berbagai pihak, baik yang sifatnya nasional, regional maupun internasional. Sehingga sekolah tidak berkutat bangga dengan prestasi yang ada saja.

d. Cultural Defence (Ketahanan Budaya), yaitu tetap menumbuhkembangkan nilai-nilai keluhuran bangsa dengan terus mengeksplorasi budaya kearifan lokal. "Local Content with a global capacity". Guru-guru boleh dari internal wilayah lokal, namun kapasitas harus global.

Visionary Leadership, yaitu Seorang pemimpin dituntut bukan hanya mampu beradaptasi dengan perubahan zaman, namun harus turut menentukan arah perubahan itu sendiri. Seorang pemimpin tertuntut bukan hanya mampu bertahan dalam dinamika perubahan, namun mampu menumbuhkembangkan sekolah (sustainable growth).

\section{KESIMPULAN DAN SARAN}

\section{A. SIMPULAN}

Setiap lembaga, institusi dan organisasi apapun namanya tentu harus melakukan perubahan, karena dinamika kehidupan bergerak terus dengan sangat cepat, Tantangannya bukan saja harus mampu beradaptasi dengan perubahan, namu juga bagaimana kemampuan menentukan arah perubahan serta memimpin perubahan, begitu pula di ke RW 05 dan Kelurahan Baktijaya Kecamatan Setu Tangerang Selatan. Paska kepemimpinan yang sangat lama tidak ada perubahan, maka ketua RW yang baru ini melakukan terobosan dengan membuat slogan BARU (Bersih - Aman - Rukun), berdasar pada ini dikembangkan kepemimpinan ke level bawahnya yaitu ke RT an sampai menyentuh dataran realitas masyarakat, Dengan membudayaan kata BARU, ketua RW berhasil mengimplementasikan nilai-nilai kemasyarakatan yang pada gilirannya tercipta nilai- nilai kepemimpinan di lapiran masyarakatnya, dengan demikian
Ketua RW 05 berhasil mengembangkan kepemimpinan berbasis budaya.

\section{B. SARAN}

Berdasarkan hasil wawancara dan FGD serta masukan-masukan dari masyarakat terutama yang dijadikan koresponden, maka disarankan: (1) Perlunya perluasan net working denga dunia luar lingkungan RW, (2) Perlunya frekuensi atau intensitas kegiatan di level ke RT dan yang makin intensif, (3) Perlunya peningkatan kualitas SDM para RT sehingga berdaya guna kepada masyarakat lebih baik

\section{DAFTAR RUJUKAN}

Adair, John. 2003. Not Bosses But Leaders. Penerbit : Great Britian Clesys. London.

Alfabeta, CV. Bandung.

Anwar, Saifudin, Reliabilitas dan Validitas, Pustaka Pelajar, Yogyakarta, 2003

Approaches. Edisi ke-2. India Sage, 2003

Cresell, John W., Research Design : Qualitatif, Quantitatif and Mixed Methods

Danu Eko Agustinova, Memahami Metode Penelitian Kualitatif Teori dan Praktik, Calpulis, Yogyakarta, 2015

Dede Andi, Muhamad Abid, Denok Sunarsi, \& Irfan Rizka Akbar. (2021). Implementasi Pendidikan Karakter Melalui Nilai-nilai Kearifan Lokal di Mts Darul Huda Kp. Cimuncang Kabupaten - Tasikmalaya. JIIP Jurnal Ilmiah Ilmu Pendidikan, 4(3), 149153. Retrieved from http://jiip.stkipyapisdompu.ac.id/jiip/inde x.php/IIIP/article/view/227

Drafke, Michael. 2009. The Human Side of Organizations.Penerbit: Prentice Hall.

Ivancevich. 2008. Organization Behavior. Penertbit: MGGraw-Hill education. New York.

Kreither, Robert. 2010. Organization Behavior. Penertbit: MGGraw-Hill education, New York.

Lepine, Colquiit.2009. Organization Behavior. Penertbit: MGGraw-Hill education, New York 
Linda Suprihatin, \& Denok Sunarsi. (2021). Pengaruh Kepemimpinan Transaksional dan Lingkungan Kerja Terhadap Kinerja Pegawai di Pusat Pendidikan dan Pelatihan Pegawai Kementerian Pendidikan dan Kebudayaan. JIIP - Jurnal Ilmiah Ilmu Pendidikan, 4(1), 78-86. Retrieved from http://jiip.stkipyapisdompu.ac.id/jiip/inde x.php/JIIP/article/view/207

Lussier, Robert. 2001. Human Relation In Organizations. Newstrom,

Moleong, Metodlogi Penelitian Kualitatif, PT. Rosda karya, Bandung, 2017

Regita Puji Agustin, Adi Suparwo, Wulan Yuliyana, Denok Sunarsi, \& Nurjaya. (2021). Pengaruh Kualitas Pelayanan terhadap Kepuasan Pelanggan serta dampaknya pada Word of Mouth Jasa
Pengurusan Nenkin di CV Speed Nenkin. JIIP - Jurnal Ilmiah Ilmu Pendidikan, 4(3), 186-190. Retrieved from http://jiip.stkipyapisdompu.ac.id/jiip/inde x.php/IIIP/article/view/249

Rusmin, Tumanggor, dkk., Ilmu Sosial \& Budaya Dasar, Cetaka ke 2 Kencana Prenada Media Gru, Jakarta, 2012.

Samiaji Sarosa, M. Info Sys, Penelitian Kualitatif Dasar Dasar, Indeks Jakarta, 2017

Sugiyono. 2013. Metode Penelitian Kuantitatif, Kualitatif, dan R\&D. Penerbit

Wahjosumidjo, Kepemimpinan dan Motivasi, Ghalia Indonesia, Jakarta, 2000

Yukl, Gary. 2010. Leadershp In Organization. Penerbit : Prentice 